\title{
Myrdal contra Ohlin: Accounting for the Sources of U.S. County Per Capita Income Convergence Using a Flexible Decomposition Approach
}

\section{E. Anthon Eff*}

\begin{abstract}
The neoclassical perspective, exemplified by Bertil Ohlin, predicts the fact of interregional per capita income convergence and is therefore often invoked in explaining its causes. However, convergence is also explained by other perspectives, such as Gunnar Myrdal's circular and cumulative causation. Applying a flexible growth-accounting decomposition to nominal per capita income changes in U.S. counties (1969-1996), this paper finds that $\beta$-convergence was generated by government transfer and wage spending, rather than the private sector forces postulated by Ohlin. Migration data suggest that the movement of retirees from rich counties to poor has been an important source of convergence.
\end{abstract}

\section{INTRODUCTION}

Does the gap between rich and poor regions grow or diminish over time? Perhaps the earliest discussion can be credited to David Hume, who posited convergence across regions based on the notion that firms tend to move out of highwage areas to regions with lower labor costs (Hume 1906, p. 28). A few decades later, Adam Smith argued that "the very unequal price of labour which we frequently find in England in places at no great distance from one another" would be narrowed by freer movement of labor between English parishes-a movement unfortunately restricted by government in the form of the "poor laws" (Smith 1937, p. 140). These views can be taken as representative of the liberal or laissezfaire tendency in classical economics: convergence is the natural outcome of a market economy, government action a cause of inequality. However, beginning with Jean Charles de Sismondi, in 1827 (Spiegel 1991, p. 302), a new type of "liberal" thinking appears in economics-one skeptical that beneficial outcomes occur spontaneously when individuals behave self-interestedly. Perhaps the most interesting split between new liberal and old liberal on the issue of interregional convergence is that between two Swedish economists - Gunnar Myrdal and Bertil Ohlin-who came up with quite contradictory ideas regarding the effects of a market economy on interregional income convergence. This paper will first discuss their ideas, and then use a new growth-accounting method to determine whose ideas are most in accord with the facts for U.S. counties from 1969 to 1996.

*Assistant Professor, Department of Economics and Finance, Middle Tennessee State University, Murfreesboro, TN. 


\section{Bertil Ohlin and Neoclassical Convergence}

Bertil Ohlin (1967) presents a view very much in the laissez-faire tradition of the classics. Basing his perspective on the classical and neoclassical notion of diminishing marginal returns, Ohlin posits that factor prices vary directly with their relative scarcity. He argues that a region will produce-for export-goods whose production requires intensive use of that region's most abundant factors. This increases demand (and price) for these abundant factors and reduces demand (and price) for scarcer factors, leading to a "tendency toward equalization of factor prices" across regions (Ohlin 1967, p. 24). If relative factor prices differ sufficiently, interregional factor movement may occur. Factor migration, when it occurs, clearly furthers equalization of returns: "factors move from countries where their prices are low to those where they are dear," so that "their scarcity and reward in the former are increased, while their prices in the latter fall" (Ohlin 1967, p. 214).

Ohlin stresses that there is only a "tendency toward equalization," and that "complete equality of factor prices is...almost unthinkable and certainly highly improbable" (Ohlin 1967, pp. 2627). The major obstacles to complete equality are transfer costs, and where these are reduced-either through removal of trade restrictions or improvement in transportation-one would expect a further narrowing of factor price differentials.

Ohlin suggests that trade in goods and factor migration would, over time, tend to diminish interregional differences in factor income. This is a prime example of a perspective that views economic change as an equilibrating, selfdampening process. Any deviation from the norm gradually erodes away through nothing more than the natural human proclivity to truck and barter. No government intervention is needed in order to promote convergence in per capita income among rich and poor regions.

\section{Gunnar Myrdal and Circular and Cumulative Causation}

Gunnar Myrdal's perspective explicitly attacks the view of economic processes as equilibrating or self-dampening, asserting that most processes exhibit characteristics of "circular and cumulative causation," so that a small initial change amplifies over time to become a substantial change (Myrdal 1957, p. 13). Applying circular and cumulative causation to regional growth processes, Myrdal maintains that market forces tend to widen interregional differences in factor income, causing rich regions to grow richer and poor regions to grow poorer. This divergence stems from two sources: external economies in the rich regions and what Myrdal terms "backwash effects," which retard growth in poor areas.

Ironically, backwash effects are the result of interregional flows of goods and factors, the very phenomena that, in neoclassical analysis, ineluctably lead to factor price convergence. A rich region will be more productive (primarily through external economies) than its poorer neighbors; its products will therefore be cheaper and will find willing buyers. (Myrdal 1957, p. 28). Trade thus expands the 
markets of firms in rich regions, while smothering industries in low-income areas.

Factor migration likewise works to the detriment of poor regions by draining them of valuable resources. Poor regions typically contain abundant labor but little capital. In the neoclassical perspective, with its assumption of diminishing marginal returns, capital would have relatively high returns in a poor region. The result is that capital migrates from rich regions to poor. Myrdal, however, disputes this, arguing that capital is attracted to rich regions, where external economies produce increasing returns (Myrdal 1957, p. 28).

Myrdal concurs with Ohlin that labor flows from low-wage to high-wage regions, but this is an even more serious drain of resources from poor areas. Those who leave are usually the most able and energetic workers and in the prime of their productive years. Those who stay are children, the elderly, and those with little ambition. This dispirited labor force, while "cheap and often docile...does not usually attract industry" (Myrdal 1957, p. 31).

As a nation becomes richer, per capita income converges across regions (Myrdal 1957, p. 34). Myrdal posits a rough schema of developmental stages: initial divergence among regions, followed by convergence. This is a widespread view among development economists and is often attributed to Jeffrey Williamson (1965) or to Simon Kuznets (1955), though Myrdal (1957, p. 33n) apparently arrived at the idea independently. In Myrdal's version of this idea, there are three main forces that foster convergence: "spread effects," "counteracting changes" in rich regions, and the rise of the welfare state.

Spread effects occur when growth in a rich region stimulates demand for the products of poor regions, such as foodstuffs or industrial raw materials. This increase in demand will set off a chain of circular and cumulative growth, making the poor region increasingly prosperous (Myrdal 1957, pp. 31-32).

"Counteracting changes" in a rich region include all those factors spontaneously generated by growth, which then act as obstacles to further growth. Among these, Myrdal mentions high wages, obsolescent equipment and structures, and a sapping of the entrepreneurial spirit as the region becomes accustomed to wealth (Myrdal 1957, pp. 35-36). In recognizing counteracting changes, Myrdal is acknowledging that equilibrating, self-dampening processes do play a role in economic growth. However, he believes "that when the main trends over somewhat longer periods are under consideration, the changes will in the main support each other and thus tend to be cumulative in their net effects" (Myrdal 1957, p. 37).

Myrdal regards the role of the "welfare state" as critical in reducing interregional per capita income disparities (Myrdal 1957, p. 39). State spending by and large favors convergence by strengthening spread effects: investment in education, transportation, and communications tends "to strengthen the forces for the centrifugal spread of economic expansion or to remove the obstacles for its operation" (Myrdal 1957, p. 34). And because growth is largely a circular and cumulative process, small government expenditures can set in motion sustained growth. 


\section{Empirical Studies of Convergence}

The utility derived from living in any region can be said to depend on three factors-nominal incomes, local prices, and local non-tradable amenities. Price data are less reliable than data for nominal income, but there have been various convergence studies that adjusted income for local price differences (e.g., Wojan 1997; Wojan and Maung 1998; Persson 1997). In Sweden-and most likely the U.S.-housing accounts for virtually all of the local price differentials (Persson 1997, p. 1838). The value of amenities is typically calculated as a "compensating differential" from local wages and housing prices (Gabriel, Mattey, and Wascher 1996). In effect, one assumes that the utility of living in all regions is about the same, and that differences in nominal income or local prices compensate for the presence of amenities. Of course, assuming that all regions have the same broadly defined living standards is the same as saying that they have already converged. For this reason, convergence in the standard of living cannot be studied.

However, the processes of convergence postulated by Myrdal and Ohlin both focus on changes in nominal income. For example, in Ohlin's view, it is the interregional comparison of nominal factor payments that defines the comparative advantage of a region: the cost of a traded product is dependent on the nominal cost of production, not on how far the worker is able to stretch each dollar of wage. Ohlin predicts specifically that nominal wages should grow more strongly in the poor region; he is silent regarding the eventual disposition of the cost of living. Thus, even though one cannot divine from the data the facts regarding convergence in standard of living, one can nevertheless infer whether Ohlin or Myrdal is more nearly correct regarding the mechanism of convergence in nominal income.

In recent years, a number of published studies have examined the degree of convergence in average wages or per capita income levels among nations (e.g., Pritchett 1995; Slaughter 1997), among states or regions within the U.S. (Amos 1988; Barro and Sala-i-Martin 1991; Browne 1980a, 1980b, 1989; Garnick 1990; Garnick and Friedenberg 1982; Loewy and Papell 1996; Carlino and Mills 1993, 1994, 1996; Crown and Wheat 1995), among subnational units within other countries-for example, Australia (Maxwell and Hite 1992), Sweden (Persson 1997), Austria (Hofer and Worgotter 1997), and Greece (Siriopoulos and Asteriou 1997)—or among regions within the European Union (e.g., MacKay 1995; Quah 1996). The results are as varied as the methodologies, economies, and time periods, though convergence is generally indicated for the U.S.

Much of this research was sparked by a recent avatar of Myrdal's theory of circular and cumulative causation-endogenous growth theory (Romer 1986)which pointed to the failure of convergence among nations as an indication that neoclassical growth theory was incorrect (Carlino and Mills 1996, pp. 565-566; Persson 1997, p. 1835). The empirical study of convergence then became a way to marshal evidence in favor of one theory or the other. That research is similar to the present paper in that convergence is examined to illuminate the validity of a pair 
of conflicting theories, theories differing in postulating increasing returns and diminishing returns.

Three measures of convergence have been widely employed (Carlino and Mills 1996, pp. 569-571):

$\sigma$-convergence: occurring when the coefficient of (interregional) variation of per capita income declines over time.

$\beta$-convergence: occurring when initial per capita income level in year $\mathrm{t}\left(\mathrm{Y}_{\mathrm{i}, \mathrm{t}}\right)$ and subsequent $\mathrm{p}$-year per capita income growth rate $\left(\mathrm{g}_{\mathrm{i}, t, t+\mathrm{p}}\right)$ are inversely related (i.e., $\beta<0$ for Equation 1 ).

$$
g_{i, t, t+p}=\alpha+\beta Y_{i, t}+e_{i, t}
$$

Stochastic convergence: occurring when per capita income levels of rich and poor regions are co-integrated.

Stochastic convergence has attracted particular interest because it examines the properties of the entire time series of per capita income measures rather than a pair of arbitrarily chosen years. However, the method is better suited to long series, rather than the 28 years examined here, and it is not helpful in uncovering the causes of convergence, only the fact of convergence. The present paper focuses on $\beta$-convergence.

The per capita income data used here represent the 3,076 counties in the lower 48 U.S. states for each year from 1969 to $1996 .{ }^{1}$ Calculating $\beta$-convergence requires one to regress the growth rate of per capita income on the initial per capita income level. As there are 378 potential growth rates (28 years, taken two at a time), there are 378 different regressions one could use to calculate $\beta .^{2}$ Table 1 presents the results for all these potential growth rates; '-' indicates that $\beta<0,{ }^{\prime}+$ ' indicates that $\beta>0$, and ' $o$ ' indicates that $\beta$ was insignificantly different from zero (at the $5 \%$ significance level). Overwhelmingly, $\beta$ turned out negative and significant; the exceptions are relatively short-horizoned growth rates, susceptible to one-time shocks.

While Table 1 provides evidence of the existence of $\beta$-convergence, it tells nothing about how that convergence came about. In order to examine the sources of convergence, the rich detail in the REIS income accounts is employed within the growth-accounting framework developed by Lynn Browne (1980a and 1980b) and Daniel Garnick (1990).

\footnotetext{
${ }^{1}$ Data are from the Bureau of Economic Analysis' (BEA) Regional Economic Information System (REIS), a CDROM with detailed regional income accounts (U.S. Department of Commerce 1998).

${ }^{2}$ Each regression was a cross section on 3,076 counties. The standard errors were corrected for heteroskedasticity using White's robust variance-covariance matrix.
} 


\section{TABLE 1}

Signs of $\beta$-Coefficient from Equation 1: All Possible Calculations U.S. Counties, 1969-1996

\begin{tabular}{|c|c|c|c|c|c|c|c|c|c|c|c|c|c|c|c|c|c|c|c|c|c|c|c|c|c|c|c|}
\hline \multicolumn{13}{|c|}{ Initial } & \multicolumn{15}{|c|}{ End Year } \\
\hline Year & 70 & 1 & 2 & 3 & 4 & 5 & 6 & 7 & 8 & 9 & 80 & 1 & 2 & 3 & 4 & 5 & 6 & 7 & 8 & 9 & 90 & 1 & 2 & 3 & 4 & 5 & 6 \\
\hline 69 & - & - & - & - & - & - & - & - & - & - & - & - & - & - & - & - & - & - & - & - & - & - & - & - & - & - & - \\
\hline 70 & & - & - & - & - & - & - & - & - & - & - & - & - & - & - & - & - & - & - & - & - & - & - & - & - & - & - \\
\hline 71 & & & - & - & - & - & - & - & - & - & - & - & - & - & - & - & - & - & - & - & - & - & - & - & - & - & - \\
\hline 72 & & & & o & - & - & - & - & - & - & - & - & - & - & - & - & - & - & - & - & - & - & - & - & - & - & - \\
\hline 73 & & & & & - & - & - & - & - & - & - & - & - & - & - & - & - & - & - & - & - & - & - & - & - & - & - \\
\hline 74 & & & & & & - & - & - & - & - & - & - & - & - & - & - & - & - & - & - & - & - & - & - & - & - & - \\
\hline 75 & & & & & & & - & - & - & - & - & - & - & - & - & - & - & - & - & - & - & - & - & - & - & - & - \\
\hline 76 & & & & & & & & - & - & - & - & - & - & - & - & - & - & - & - & - & - & - & - & - & - & - & - \\
\hline 77 & & & & & & & & & - & - & - & - & - & - & - & - & - & - & - & - & - & - & - & - & - & - & - \\
\hline 78 & & & & & & & & & & - & - & - & - & - & - & - & - & - & - & - & - & - & - & - & - & - & - \\
\hline 79 & & & & & & & & & & & - & - & - & - & - & - & - & - & - & - & - & - & - & - & - & - & - \\
\hline 80 & & & & & & & & & & & & - & - & - & - & - & - & - & - & - & - & - & - & - & - & - & - \\
\hline 81 & & & & & & & & & & & & & - & - & - & - & - & - & - & - & - & - & - & - & - & - & - \\
\hline 82 & & & & & & & & & & & & & & - & - & - & - & - & - & - & - & - & - & - & - & - & - \\
\hline 83 & & & & & & & & & & & & & & & - & - & - & - & - & - & - & - & - & - & - & - & - \\
\hline 84 & & & & & & & & & & & & & & & & - & - & - & - & - & - & - & - & - & - & - & - \\
\hline 85 & & & & & & & & & & & & & & & & & - & - & - & - & - & - & - & - & - & - & - \\
\hline 86 & & & & & & & & & & & & & & & & & & - & - & - & - & - & - & - & - & - & - \\
\hline 87 & & & & & & & & & & & & & & & & & & & o & - & - & - & - & - & - & - & - \\
\hline 88 & & & & & & & & & & & & & & & & & & & & - & - & - & - & - & - & - & - \\
\hline 89 & & & & & & & & & & & & & & & & & & & & & - & - & - & - & - & - & - \\
\hline 90 & & & & & & & & & & & & & & & & & & & & & & - & - & - & - & - & - \\
\hline 91 & & & & & & & & & & & & & & & & & & & & & & & - & - & - & - & - \\
\hline 92 & & & & & & & & & & & & & & & & & & & & & & & & o & - & o & o \\
\hline 93 & & & & & & & & & & & & & & & & & & & & & & & & & - & - & - \\
\hline 94 & & & & & & & & & & & & & & & & & & & & & & & & & & & + \\
\hline 95 & & & & & & & & & & & & & & & & & & & & & & & & & & & o \\
\hline
\end{tabular}

$(-)=$ significant and negative; $(+)=$ significant and positive; $(0)=$ not significant.

Data from REIS, Table CA30.

$\mathrm{N}=3,076$ U.S. Counties (excludes AK and HI)

Standard errors corrected for heteroskedasticity using White's robust variance-covariance matrix.

\section{GROWTH ACCOUNTING}

A growth-accounting framework (Browne 1980a and 1980b; Garnick 1990) allows per capita income growth to be decomposed into its constituent elements. One can thus calculate the contributions to per capita income growth of government expenditures and private sector employment. By comparing the contributions in low-income regions with those in high-income regions, it becomes possible to determine whether these income sources promote divergence or convergence across regions.

Data on income by component for U.S. counties are available from REIS. Equation 2 presents the decomposition of per capita income into its constituent parts, using the available detail from REIS. ${ }^{3}$ The terms in the numerator cancel out all terms in the denominator except population. When the remaining numerator terms are summed, the equation simplifies to personal income divided by population.

${ }^{3}$ Disclosure rules do not allow full use of REIS' detail. Eight sectors had full disclosure or near full disclosure, in that the sum of individual county income and employment added up to at least 99.99 percent of the U.S. value. These eight sectors are farm, FIRE, retail, manufacturing, military, federal civilian, state and local government, and an aggregate of all other sectors. 


$$
\begin{aligned}
& \frac{Y}{P}=\frac{L}{P} \sum_{j \in \text { Earnings }} \frac{L_{j}}{L} \frac{W_{j}}{L_{j}}-\frac{S}{P}+\frac{R}{P}+\frac{D}{P}+\sum_{i \in \text { Transfers }} \frac{T_{i}}{P} \\
& Y=\text { Total personal income } \\
& P=\text { Population } \\
& L=\text { Total working persons (includes both employees and proprietors) } \\
& L_{j}=\text { Persons working in employment category } j \\
& W_{j}=\text { Earnings from working in employment category } j \\
& S=\text { Payroll taxes (FICA) } \\
& R=\text { Residence adjustment, representing net inflow of earnings from } \\
& D=\text { employment elsewhere } \\
& T_{i}=\text { Dividends, interest, and rent }
\end{aligned}
$$

Decomposition of per capita income growth is fairly straightforward if per capita income level is expressed either as the sums of components or as the products of components. If expressed as sums, the weighted discrete growth rates of the components sum to the total discrete growth rate; if expressed as products, the total exponential growth rate equals the sum of the components' exponential growth rates. However, difficulties arise if both product and sum terms appear, as in Equation 2. This creates interaction terms among the components, which must be split apart and assigned to one component or another. For this reason, earlier attempts at growth accounting avoided specifications with both product and sum terms. However, it would be useful for purposes of understanding the sources of per capita income changes if it were possible to employ greater flexibility in the specification of per capita income sources.

In what follows, a technique is proposed to allocate interaction terms to per capita income components. Equation 3 shows the derivation of the discrete growth rate from Equation 2:

$$
\begin{gathered}
\left(\Delta \frac{Y}{P}\right) \frac{P}{Y}=\frac{P}{Y}\left[\left(\frac{L}{P}+\Delta \frac{L}{P}\right)_{j \in \text { Earnings }}\left(\frac{L_{j}}{L}+\Delta \frac{L_{j}}{L}\right)\left(\frac{W_{j}}{L_{j}}+\Delta \frac{W_{j}}{L_{j}}\right)-\left(\frac{S}{P}+\Delta \frac{S}{P}\right)+\right. \\
\left.\left(\frac{R}{P}+\Delta \frac{R}{P}\right)+\left(\frac{D}{P}+\Delta \frac{D}{P}\right)+\sum_{i \in \text { Transfers }}\left(\frac{T_{i}}{P}+\Delta \frac{T_{i}}{P}\right)-\frac{Y}{P}\right]
\end{gathered}
$$

which, after some substitution, gives (the dots over a ratio indicate the discrete growth rate): 


$$
\begin{aligned}
\left(\frac{\dot{Y}}{P}\right)= & \sum_{j \in \text { Earnings }} \frac{W_{j}}{Y}\left[\left(\frac{W_{j}}{L_{j}}\right)+\left(\frac{\dot{L}_{j}}{L}\right)+\left(\frac{\dot{L}}{P}\right)+\left(\frac{W_{j}}{L_{j}}\right)\left(\frac{\dot{L}_{j}}{L}\right)+\left(\frac{\dot{L}}{P}\right)\left(\frac{W_{j}}{L_{j}}\right)+\left(\frac{\dot{L}}{P}\right)\left(\frac{\dot{L}_{j}}{L}\right)+\right. \\
& \left.\left(\frac{\dot{L}}{P}\right)\left(\frac{\dot{W}_{j}}{L_{j}}\right)\left(\frac{\dot{L}_{j}}{L}\right)\right]-\frac{S}{Y}\left(\frac{\dot{S}}{P}\right)+\frac{R}{Y}\left(\frac{\dot{R}}{P}\right)+\frac{D}{Y}\left(\frac{\dot{D}}{P}\right)+\sum_{i \in \text { Transfers }} \frac{T_{i}}{Y}\left(\frac{\dot{T}_{i}}{P}\right)
\end{aligned}
$$

The interaction terms are those instances where two or more growth rates are multiplied. The contributions of the components lacking interaction terms are calculated directly:

$$
c\left(\frac{T_{i}}{P}\right)=\frac{T_{i}}{Y}\left(\frac{T_{i}}{P}\right) \text { Contribution of transfer } i \text { to per capita income growth. }
$$$$
c\left(\frac{D}{P}\right)=\frac{D}{Y}\left(\frac{\dot{D}}{P}\right) \text { Contribution of dividends, interest, and rent. }
$$

$$
c\left(\frac{R}{P}\right)=\frac{R}{Y}\left(\frac{\dot{R}}{P}\right) \quad \text { Contribution of residence adjustment. }
$$

$$
c\left(\frac{S}{P}\right)=-\frac{S}{Y}\left(\frac{\dot{S}}{P}\right) \text { Contribution of payroll taxes. }
$$

Calculation of the contribution of components sharing an interaction term poses a problem: some portion of the interaction term must be allocated to each of these. Accountants have long recognized that any allocation procedure is in essence arbitrary (Thomas 1969). In some contexts-such as neoclassical growth theory (Solow 1957) - economic theory can be used to provide a reasonable basis for an allocation. In this particular case there are no obvious theoretical guidelines. Instead, a set of criteria was postulated, which it seemed that any allocation procedure should meet.

1. The interaction terms should be exhausted by the allocations, so that the sum of all adjusted contributions exactly equals the total per capita income growth rate. After all, the whole point of the allocation exercise is to account completely for the sources of per capita income growth.

2. As a corollary to the exhaustion condition, the decomposition procedure should be consistent in that a sum of adjusted contributions should equal the aggregate contribution for these components. For example, the sums of the contributions of all $\left(\mathrm{W}_{\mathrm{j}} / \mathrm{L}_{\mathrm{j}}\right),\left(\mathrm{L}_{\mathrm{j}} / \mathrm{L}\right)$, and $(\mathrm{L} / \mathrm{P})$ should sum to the contribution of $(\mathrm{W} / \mathrm{P})$.

3. The sign of the interaction term should be the sign of the portion allocated to each component. Suppose that in the above example the growth rate of $\left(\mathrm{L}_{\mathrm{j}} / \mathrm{L}\right)$ 
was negative, while the growth rate of $\left(\mathrm{W}_{\mathrm{j}} / \mathrm{L}_{\mathrm{j}}\right)$ was positive, so that the interaction term between these two is negative. This rule would require that the contributions of $\left(\mathrm{L}_{\mathrm{j}} / \mathrm{L}\right)$ and $\left(\mathrm{W}_{\mathrm{j}} / \mathrm{L}_{\mathrm{j}}\right)$ both decline. The reasoning is that the interaction effect worsens the negative impact of $\left(\mathrm{L}_{\mathrm{j}} / \mathrm{L}\right)$ and reduces the beneficial effect of $\left(\mathrm{W}_{\mathrm{j}} / \mathrm{L}_{\mathrm{j}}\right)$.

4. The portion of the interaction term allocated to a component should vary directly with the absolute value of the growth rate of that component. Thus, if $\left(\mathrm{W}_{\mathrm{j}} / \mathrm{L}_{\mathrm{j}}\right)$ experienced a very small change, but $\left(\mathrm{L}_{\mathrm{j}} / \mathrm{L}\right)$ a large change, more of the interaction term should be allocated to $\left(\mathrm{L}_{\mathrm{j}} / \mathrm{L}\right)$.

Employing these criteria, the following allocation scheme was adopted: Contribution of average wages in sector $\mathrm{j}$ :

$$
c\left(\frac{W_{j}}{L_{j}}\right)=\frac{W_{j}}{Y}\left(\frac{W_{j}}{L_{j}}\right)\left[1+\alpha_{1 j}\left(\frac{\dot{L_{j}}}{L}\right)+\alpha_{2 j}\left(\frac{\dot{L}}{P}\right)+\alpha_{3 j}\left(\frac{\dot{L_{j}}}{L}\right)\left(\frac{\dot{L}}{P}\right)\right],
$$

where $\alpha_{1 j}=\frac{\left|\left(\frac{\dot{W}_{j}}{L_{j}}\right)\right|}{\left|\left(\frac{\dot{W}_{j}}{L_{j}}\right)\right|+\left|\left(\frac{\dot{L}_{j}}{L_{j}}\right)\right|}, \alpha_{2 j}=\frac{\left|\left(\frac{\dot{W}_{j}}{L_{j}}\right)\right|}{\left|\left(\frac{\dot{W}_{j}}{L_{j}}\right)\right|+\left|\left(\frac{\dot{L}}{P}\right)\right|}, \alpha_{3 j}=\frac{\left|\left(\frac{\mathrm{W}_{j}}{L_{j}}\right)\right|}{\left|\left(\frac{\dot{W}_{j}}{L_{j}}\right)\right|+\left|\left(\frac{\dot{L}_{j}}{\mathrm{~L}}\right)\right|+\left|\left(\frac{\dot{L}}{P}\right)\right|}$.

Contribution of sector j's employment share:

$$
c\left(\frac{L_{j}}{L}\right)=\frac{W_{j}}{Y}\left(\frac{\dot{L_{j}}}{L}\right)\left[1+\beta_{1 j}\left(\frac{\dot{W}_{i}}{L_{j}}\right)+\beta_{2 j}\left(\frac{\dot{L}}{P}\right)+\beta_{3 j}\left(\frac{\dot{W}_{j}}{L_{j}}\right)\left(\frac{\dot{L}}{P}\right)\right],
$$

where $\beta_{1 j}=\frac{\left|\left(\frac{\dot{L}_{j}}{\mathrm{~L}}\right)\right|}{\left|\left(\frac{\dot{W}_{j}}{L_{j}}\right)\right|+\left|\left(\frac{\dot{L}_{j}}{L}\right)\right|}, \beta_{2 j}=\frac{\left|\left(\frac{\dot{L}_{j}}{\mathrm{~L}}\right)\right|}{\left|\left(\frac{\dot{L_{j}}}{\mathrm{~L}}\right)\right|+\left|\left(\frac{\dot{L}}{P}\right)\right|}, \beta_{1 j}=\frac{\left|\left(\frac{\dot{L}_{j}}{\mathrm{~L}}\right)\right|}{\left|\left(\frac{\dot{W}_{j}}{L_{j}}\right)\right|+\left|\left(\frac{\dot{L}_{j}}{L}\right)\right|+\left|\left(\frac{\dot{L}}{P}\right)\right|}$. 
Contribution of employment as share of the population:

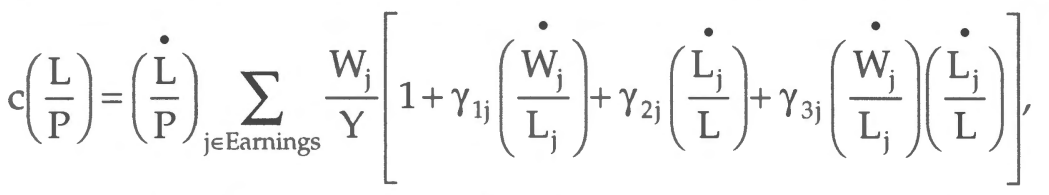

where $\gamma_{1 j}=\frac{\left|\left(\frac{\dot{L}}{P}\right)\right|}{\left|\left(\frac{\dot{W}_{j}}{L_{j}}\right)\right|+\left|\left(\frac{\dot{L}}{P}\right)\right|}, \gamma_{2 j}=\frac{\left|\left(\frac{\dot{L}}{P}\right)\right|}{\left|\left(\frac{\dot{L}_{j}}{L}\right)\right|+\left|\left(\frac{\dot{L}}{P}\right)\right|}, \gamma_{3 j}=\frac{\left|\left(\frac{\dot{L}}{P}\right)\right|}{\left|\left(\frac{\mathrm{W}_{j}}{L_{j}}\right)\right|+\left|\left(\frac{\dot{L}_{j}}{L}\right)\right|+\left|\left(\frac{\dot{L}}{P}\right)\right|}$.

\section{Rich and Poor Regions}

By separating the U.S. into three regions of high, middle, and low per capita income and then applying the growth-accounting method detailed above, this paper will examine the sources of per capita income growth and determine which of those sources contributed to $\beta$-convergence between the rich and poor regions. This study differs from previous work in that it examines the county level in order to include with greater precision the relevant high- and low-income regions. The data are drawn from REIS (U.S. Department of Commerce 1998) and include all quantities in Equation 2 for 1969 and 1996. Income measures from 1969 were inflated to 1996 prices using the implicit GDP consumption deflator. The resulting figures are "real" only in the sense that average national price changes over the 28 years have been removed-the interregional price differentials remain.

Each county was ranked according to its 1969 per capita income level. Then, these ranked counties were aggregated into three groups: a high-, middle-, and low-income group. While the ranks are objective, the lines of demarcation between the groups could reasonably be drawn in various ways, making group membership somewhat subjective. This raises the problem that results may be an artifact of a particular way of assigning group membership and not robust over other assignment methods. This problem of subjectivity was addressed by employing three different rules for assigning group membership and conducting all subsequent analysis on each of these assignment schemes. ${ }^{5}$ Definitive results should be robust across these three different ways of partitioning the nation into income regions.

1. Each group has an equal number of persons.

2. Each group has an equal number of counties.

3. The middle income group contains all those counties with per capita income within one standard deviation of the mean.

\footnotetext{
${ }^{4}$ There are 3,076 counties in the data set, which includes all counties in the contiguous U.S.

${ }^{5}$ There seems to be no a priori reason to prefer one assignment scheme to another-different preferences might depend on how one falls on the "people vs. places" issue (Bolton 1992; Winnick 1968).
} 
The three assignment schemes produce very different landscapes, as seen on the accompanying maps. In general, high-income counties tend to be urbanized while low-income counties are rural. The lowest income counties are concentrated in the deep South cotton belt and the Appalachians, with smaller clusters in south Texas and the Four Corners region-all problem areas since at least the 1920s (Hoover 1963, pp. 200-207).

Figure 1: National, State, and Substate Housing Start Figures
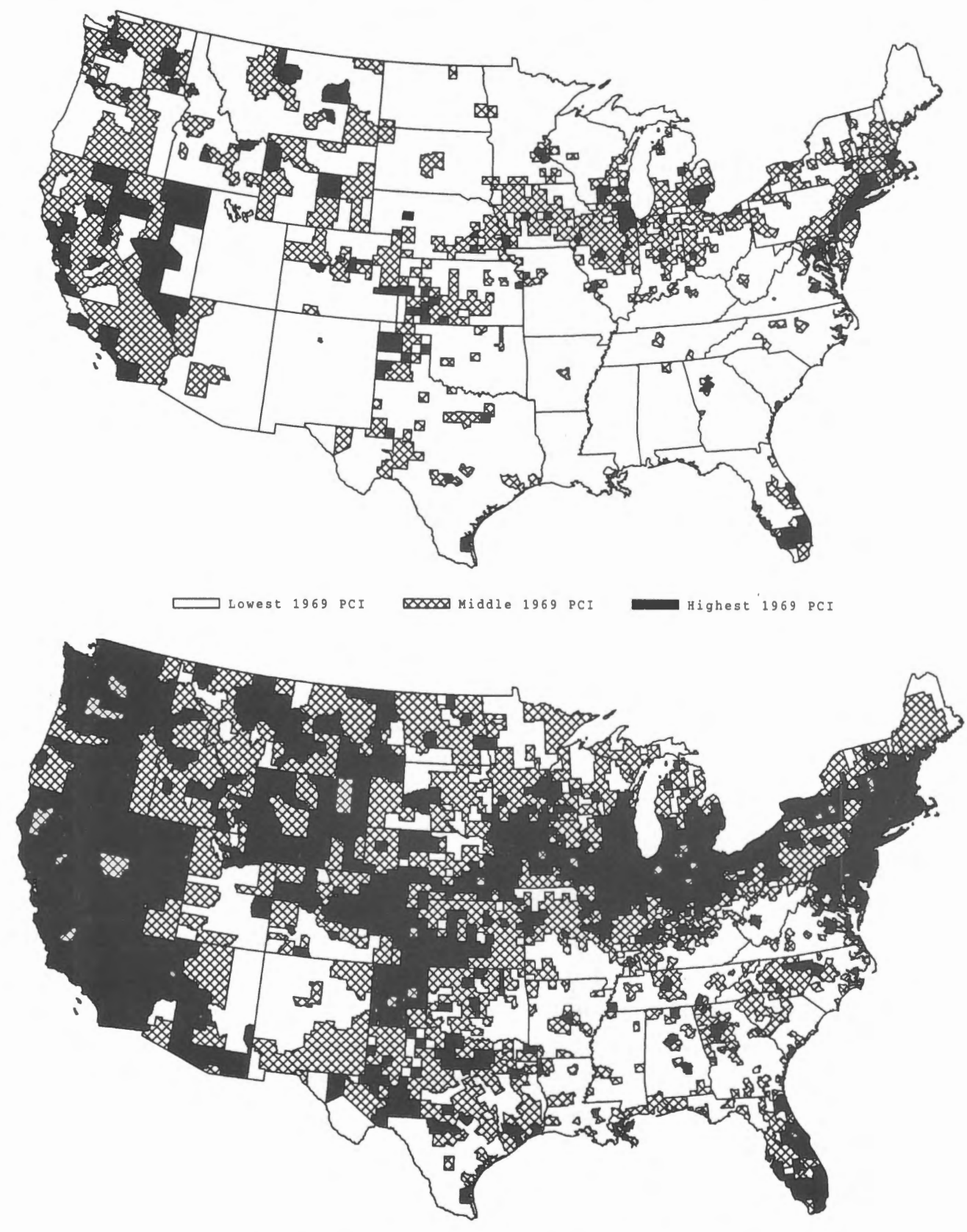


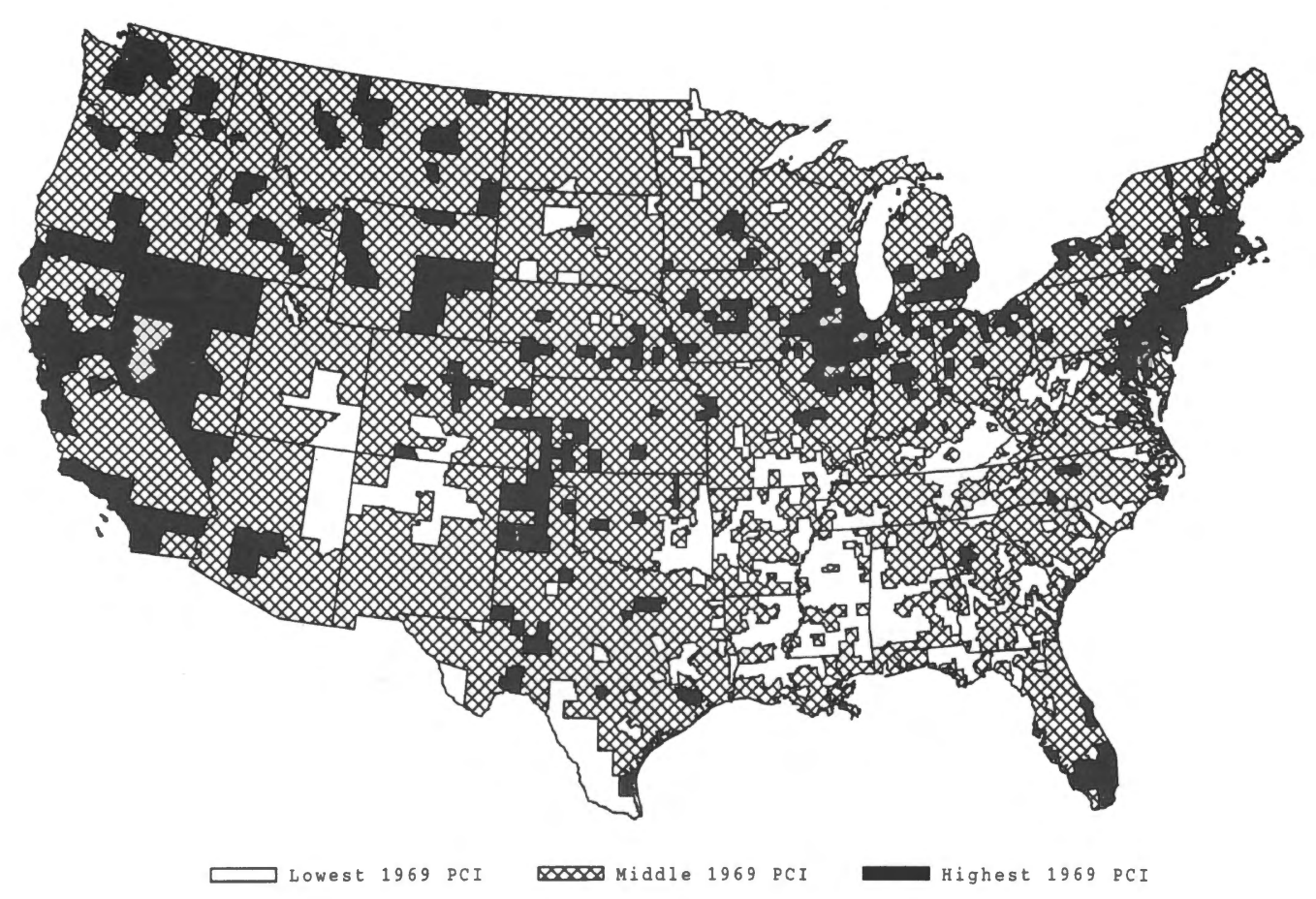

\section{Growth Accounting Results}

Table 2 applies the growth-accounting framework to show the extent to which these sources contribute to per capita income convergence for each of the three group assignment schemes. For each scheme, three columns are presented. First, figures for the highest income region are presented, then figures for the lowest income region, and finally, the difference between the two (subtracting lowest from highest). A negative difference indicates a tendency toward convergence, since growth of the income component is greater in the low-income region. Definitive results should be robust across all assignment schemes.

Between 1969 and 1996 the gap between the rich and poor regions grew in absolute terms, but convergence was nevertheless promoted since per capita income grew at a greater rate in the poor region. Two calculations were made to give insight into the strength of that convergence. The first is the number of years necessary for parity to occur, and the second is the per capita income level at parity. They show that convergence is far from dramatic-parity requires at least 100 years and a per capita income over six times 1996 levels.

Table 2 separates government components of per capita income from private sector or market sources. For all assignment schemes, government sources contributed to convergence. Transfers contributed over twice as much to per capita income growth in poor regions, with the greatest differentials in retirement and disability and in medical payments per capita. Government employment practices also contributed to convergence, with the greatest contribution coming from military employment. 


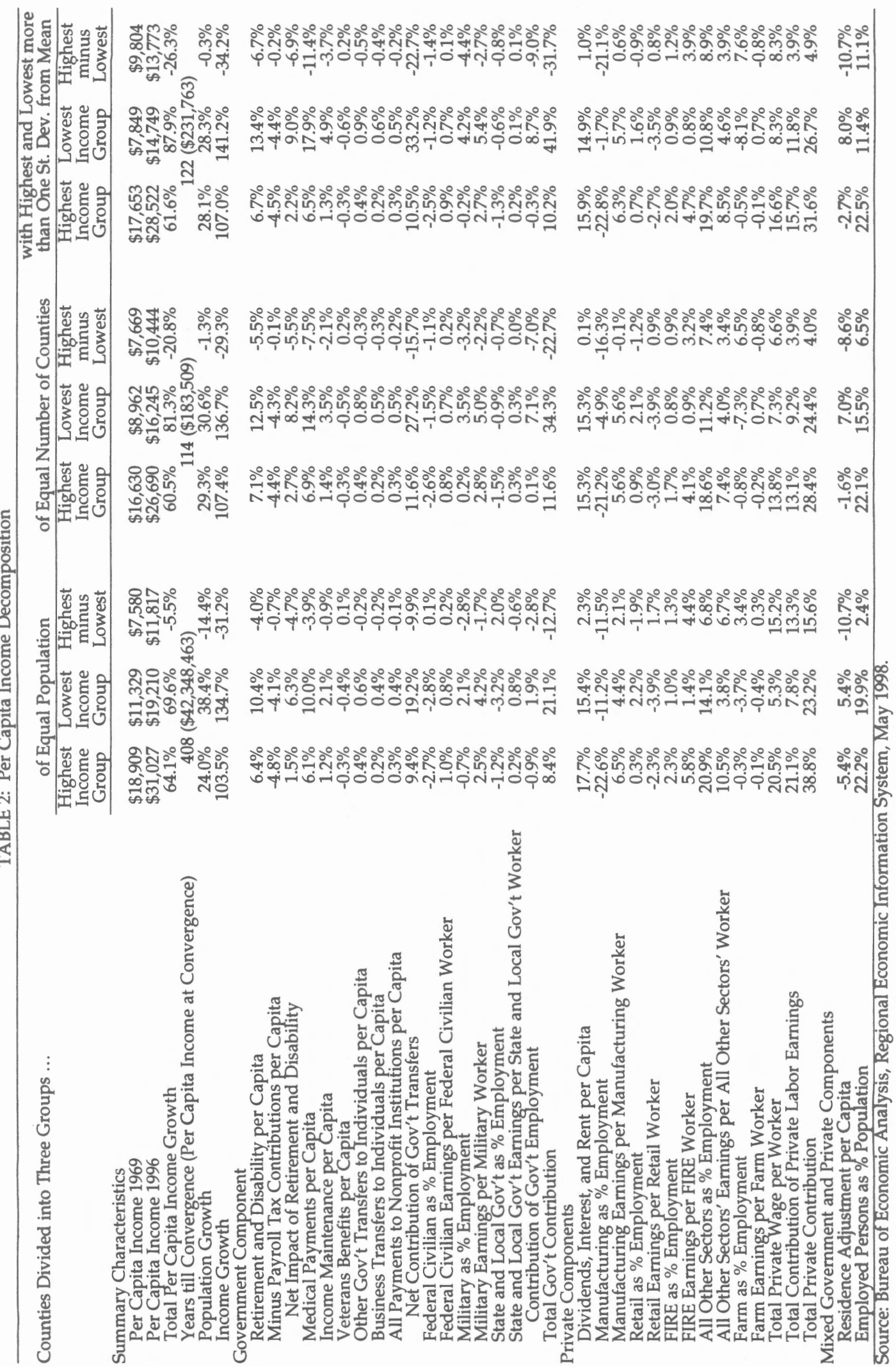


Overall, private sources contributed to divergence. Dividends, interest, and rent added more to per capita income growth in rich regions than in poor. These returns to owners of capital and land represent factors that need not be employed in the same region as an owner's residence. The observed pattern of greater growth in rich counties could be consistent with either Myrdal or Ohlinthe former if the capital is actually employed in the same region, the latter if employed in poorer counties.

Of the five private employment sectors, manufacturing and retail promoted convergence, while FIRE, farm, and combined all other sectors (which includes both services and TCPU), promoted divergence. Manufacturing shrank as a share of employment in all regions, but shrank more in rich regions (this is consistent with the broad trend of manufacturing dispersal to lower-wage rural and southern locations); however, average manufacturing wages grew more in rich regions. On balance, manufacturing as a share of employment shrank so much that the contribution of manufacturing decreased per capita income in both regions.

Service-related sectors (FIRE and all other sectors) experienced both high employment growth and high average wage growth, and these effects were stronger in the rich region. This is consistent with the observed trend of emerging "producer services" locating in places with agglomeration advantages (Hansen 1994).

Farm employment shares declined in both the rich and poor regions, though by much more in the poor region, which had begun the period with a high farm population. Movement off the farm is perhaps the most important factor in regional convergence early in this century (Borts and Stein 1964), but even the late and dramatic demise of sharecropping had largely run its course before 1969 (Crown and Wheat 1995, p. 534).

Residence adjustment, employment as a percent of the population, and payroll taxes are all intimately related. Residents of poor regions increasingly work in rich regions (most clearly seen in the residence adjustment figures), pay payroll taxes there, and are counted as part of the employment (but not the population) for the rich region's employment to population ratio. The residence adjustment is a clear example of a Myrdalian spread effect: government spending on transportation and education creates in poor counties a workforce able to commute to rich counties and work there.

One reasonable question is the extent to which these changes reflect only economic development in the Southeast-after all, most of the South falls into the lowest income group. Table 3 repeats the process for three major regions of the U.S.: the Southeast, Northeast, and West. ${ }^{6}$ The table reports only the difference between the richest and poorest counties within each region. As before, a negative quantity indicates a force promoting convergence. In general, the Northeast

${ }^{6}$ The East consists of BEA regions New England (1), Mideast (2), Great Lakes (3), and three states from the Plains (4) region: Missouri, Iowa, and Minnesota. The South consists of BEA region Southeast (5). The West consists of all the remaining states (except Alaska and Hawaii). Within each of these regions, three groups of counties were created, using three different assignment schemes, in the same manner as was earlier done for the U.S. 


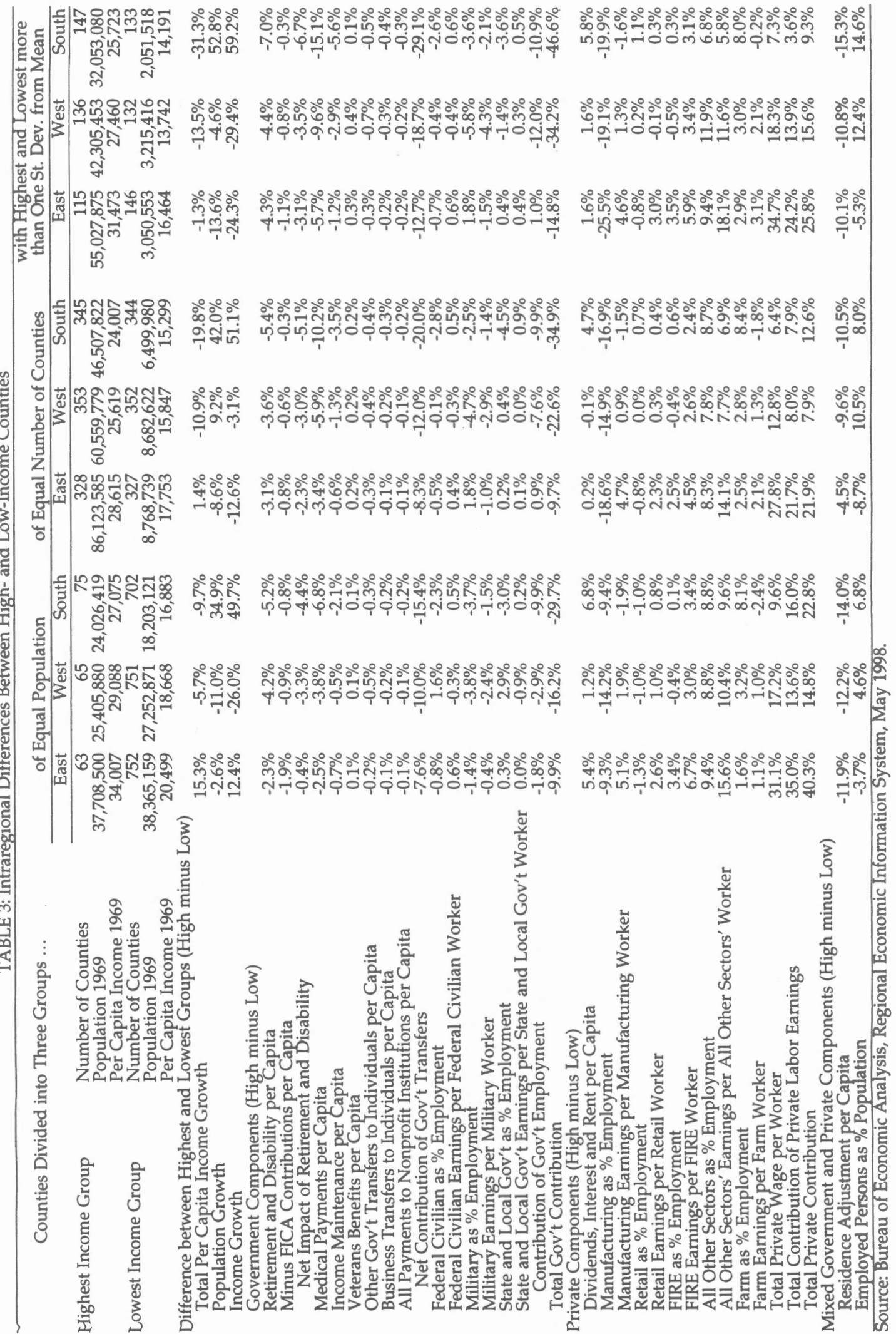


displays some tendency for divergence, while the other two regions exhibit clear convergence-a pattern consistent with the findings of Amos (1988), who amended the Kuznets-Williamson-Myrdal thesis of divergence followed by convergence to posit that divergence reappears in the most mature economies. Within each major region, as within the U.S. as a whole, the government contribution promotes convergence while the private contribution promotes divergence.

It appears from these figures that Myrdal's views are more correct than those of Ohlin. First, government income sources are clearly the main impetus for convergence; second, growth of average private sector wages was greater in rich counties than in poor. These results are robust across all assignment schemes, both in the U.S. as a whole and within each of its major regions. The tendency toward convergence, while predicted by Ohlin's analysis, was due to factors very different from those he postulated.

\section{The Full Impact of Government Taxes and Expenditures}

Many dimensions of government's economic impact cannot be seen in these data. Government wages and transfers in poor regions should set in motion a circle of cumulative economic growth so that subsequent rounds of growth put income into the hands of the private sector. Thus, at least part of the private sector income growth in poor regions would not have occurred had there not been those initial dollars spent on government employees or transfer recipients. It is impossible to identify government-generated private income short of calculating multipliers for exogenous government net expenditures for each county: However, it is clear that the private income source differential would have been greater without the government spending.

Government also makes expenditures at the local level that are not direct payments to income. For example, procurement spending goes to local firms, whose value-added contributes to local income. Again, this spending generates a circle of cumulative growth, and all these additions to local income are tallied in the statistics as private income thus giving private sources credit for income generated by government. Of particular importance may be spending on road construction, which opens poor counties to spread effects from the rich.

Data on federal government expenditures at the county level are available for the last half of our time period. Table 4 reports some figures from the Consolidated Federal Funds Reports (CFFR) for 1984 to 1996.7 Total federal government spending per capita in 1984 is highest in the rich counties, led by procurement, though highway spending and retirement and disability spending are higher per person in poor counties. However, growth of federal expenditures per capita is considerably higher in low-income counties. Of particular importance are grants, retirement and disability, and procurement. Thus, there is a clear

${ }^{7}$ Each of the annual CFFR files contains a field for type of expenditure and another field for specific program. Highway spending is a specific program, but direct payments, grants, procurement, and wages are all types of expenditure. For each county, all expenditures were summed by type and then converted to 1996 dollars using the GDP implicit consumption deflator. These figures should be definitive for federal expenditures at the county level, though there were some expenditures that could not be matched to any specific county. For additional information see <http://www.census.gov/govs/cffr/97cffdoc.pdf>. 


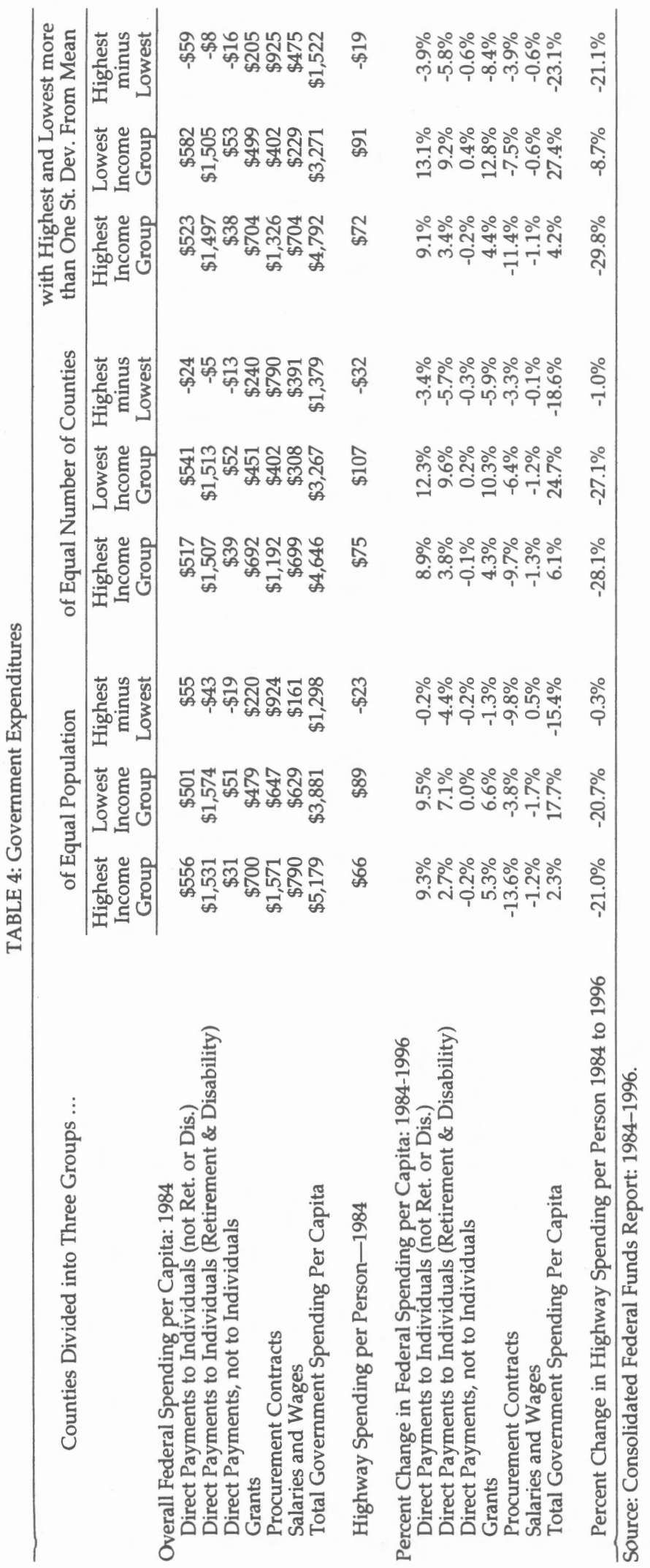


tendency toward convergence in per capita federal expenditures between rich and poor regions.

\section{Population Changes and Per Capita Income Changes}

Population changes could have important effects on per capita income. Table 3 shows that population grew more rapidly in the low-income counties, but does not specify the source of this growth (it could stem from natural increase, international migration, or domestic migration). A high rate of natural increase would have a dampening effect on per capita income growth, since it would imply the addition of population too young to obtain earnings (thus increasing per capita income's denominator and adding nothing to the numerator). In-migration, on the other hand, would presumably add adults, who are capable of work and able to increase per capita income. Table 5 examines a variety of data sources to reveal some features of population change in the richest and poorest region.

For the period 1990 to 1997 , there are county-level data detailing the sources of demographic change. ${ }^{8}$ While these represent only part of the 1969 to 1996 period, they may be indicative of the overall pattern. The richest region had the highest rate of natural increase and the highest population growth due to international immigration. However, it leaked population massively through domestic migration, causing the poorest region to pull ahead in overall population growth.

What kinds of people were involved in this domestic migration? The 1990 census provides a detailed description of intercounty migration between 1985 and $1990 .{ }^{9}$ Again, these data apply to only a portion of the overall period, but they are probably suggestive of the general pattern. Table 5 shows net migration for each educational category as a percent of total 1985 population aged 25 to 64 , and it shows net migration for each age group as a percent of 1985 persons within the age group. The richest region experienced net out-migration of all educational levels except those with a bachelor's degree or higher. This is startling confirmation of Myrdal's argument that the highest skilled are most likely to leave a lowincome region for work in a high-income region. The age distribution of these migrants show that only the cohort aged 25 to 29 exhibited net in-migration to the rich region, while out-migration was especially strong for persons aged 55 to 69 . Clearly, recent college graduates elect to move to rich regions, while retirees move to poor regions.

Among economists, most thinking of migration as the motor of convergence focuses on the movement of workers and firms (e.g., Horn 1993, p. 327). Here, though, the movement of workers clearly favors divergence: growth in high-wage jobs, a growth fueled by the in-migration of recent college graduates

\footnotetext{
${ }^{8}$ These data and their documentation are found at <http://www.census.gov/population/www/estimates/countypop.html>. A similar file covers the period 1980 to 1990, but does not separate domestic from international migration. Table 5 reports total 1990-1997 change in each category, divided by the total number of persons in 1990.

${ }^{9}$ Henk Meij of the Center for International Earth Science Information Network (CIESIN) and John Blodgett of the University of Missouri-St. Louis put together the STP28 county-to-county migration files used for Table 5. These data are found on the CIESIN web site <http://www.ciesin.org/datasets/us-demog/stp-home.html>.
} 


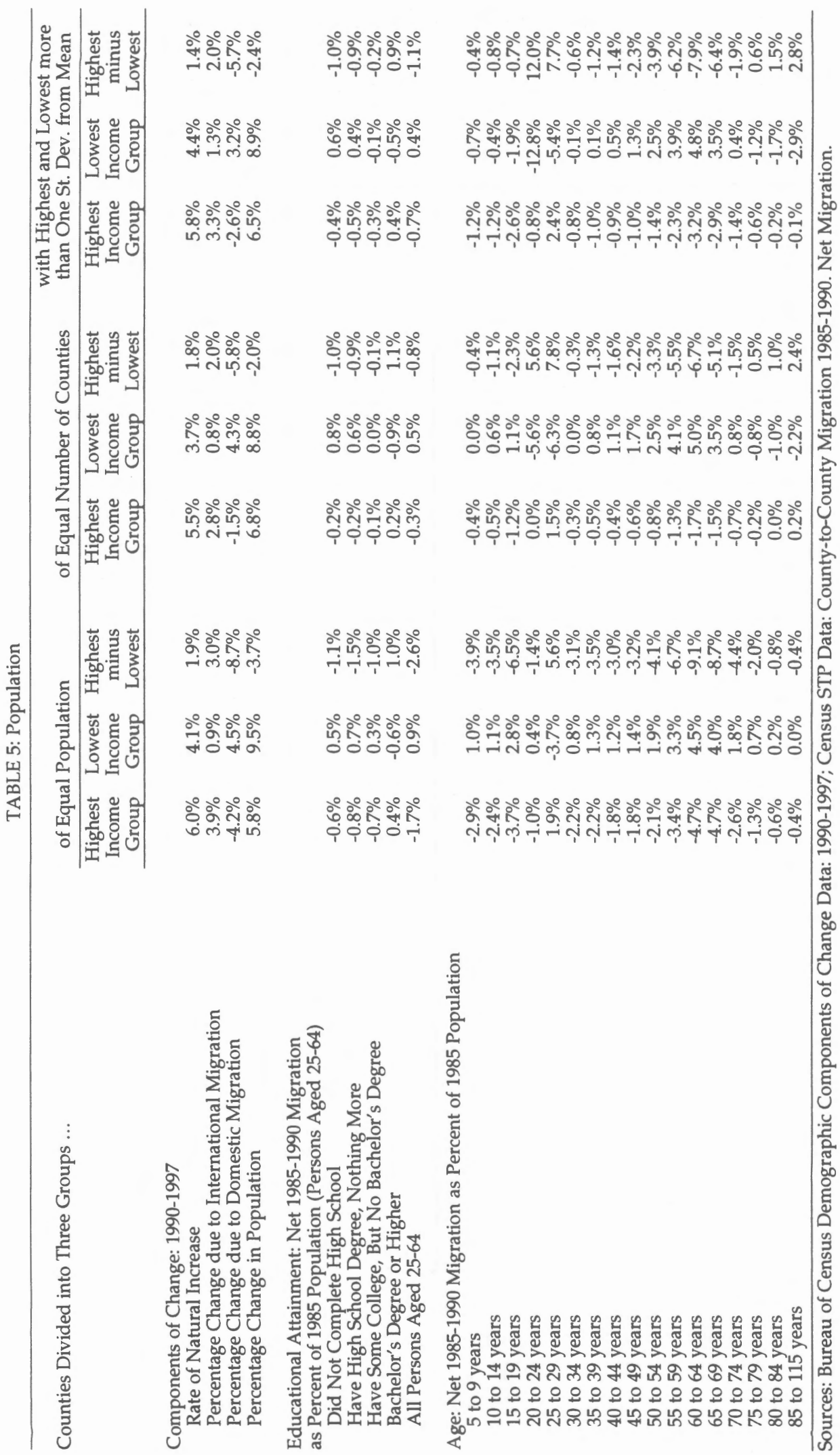


able to take these jobs, was highest in rich regions. It is migration related to consumption, not production-or the migration of retirees, not workers-that favors convergence. Tables 2 and 3 show that retirement and disability transfers promoted convergence primarily because of growth of benefits in poor counties, not growth of payroll taxes in rich counties. Table 5 shows that those benefits grew because of the migration patterns of persons aged 55 to 69 .

Within regional economics, Ohlin's views on the effect of migration on earnings convergence have long been recognized as perhaps a bit too simple and unrealistic. August Lösch-who counted Ohlin as an important influence (Lösch 1954, pp. ix, x, 24n, 103, 104n, 223n)—argues that labor always moves to maximize utility, never nominal wages (Lösch 1954, p. 241). After an episode of migration, "the new situation is characterized as little as the old by an interlocal equalization of wages... . In most cases all that can be established is that migration takes place away from regions of falling wages and toward those where wages are rising, though it cannot be said in general where incoming migrants are from or whither outgoing ones are bound" (Lösch 1954, p. 306). Arguing that Ohlin "overemphasizes supply, as though demand were less important" (Lösch 1954, p. 252n), Lösch points out that purchasing power follows migrants, causing capital to follow as well, so that capital and labor move in the same direction. Therefore, "it is not correct to say that migrations continue until wages and interest are everywhere equal once more. They need be equal in neither the old nor the new equilibrium" (Lösch 1954, pp. 306-307).

Empirical work appears to support Lösch. In general, previous studies have failed to show that migration fosters convergence (Persson 1997, p. 1851). This failure could be due to an emphasis on the wrong kind of migration (on workers driven by wages instead of on retirees driven by local prices and nontradable amenities) and on the wrong kind of convergence (on average earnings rather than on per capita income).

\section{DISCUSSION}

These results support Gunnar Myrdal's perspective on interregional relations and economic development. The notion of increasing returns, fundamental to this perspective, has had many other adherents in this century, from Allyn Young (1928) to endogenous growth theory (Romer 1986; Arthur 1988). And though this perspective flies in the face of neoclassical analysis, which is based on diminishing returns, there has been recognition by neoclassical economists as far back as Alfred Marshall (1920, appendix H) that increasing returns are important. Within regional economics, it has long been recognized (Beckman 1968, pp. 105106; Richardson 1979, p. 107) that the spatial economy displays increasing returns, particularly the phenomenon of agglomeration economies.

The importance of government transfers confirms the findings of Carlino and Mills (1996, p. 586). As MacKay (1995, p. 218) notes, transfers promote convergence not because convergence is an explicit policy goal, but because it occurs 
incidental to other objectives. Those objectives may be policy driven or they may be political..$^{10}$ Perhaps the most important government-influenced convergence mechanism is through retirement and disability payments and the way in which these are distributed through migration.

Migration is a topic about which even Myrdal had it partly wrong: the poor region experiences a net in-migration, not a net out-migration. Myrdal was correct that the highest quality workers would abandon the poor region for jobs in the rich, but he failed to see that large numbers of other persons, particularly retirees, would move into the poor region. Retirees are in a peculiar position in that, since they are not seeking work, they find nominal wages irrelevant. Without the need to consider nominal wages, the poor region apparently gains in attractiveness, presumably because of amenities and low prices.

\section{CONCLUSIONS}

The standard neoclassical perspective, as presented by Bertil Ohlin, predicts the fact of convergence and therefore is often invoked in explaining its causes. However, the spatial economy violates many of the assumptions of neoclassical analysis (Richardson 1979, p. 107), and the fact of convergence is also consistent with some perspectives based on increasing returns (Persson 1997, p. 1836; Carlino and Mills 1993). Thus, the fact of convergence does not necessarily mean that the mechanism postulated by neoclassical analysis is correct. This paper showed that convergence in nominal per capita income did occur during the period 1969 to 1996 across U.S. counties. However, examining the sources of convergence, it was found that Gunnar Myrdal's views are consistent with the facts: average private wage growth was higher in rich counties; government wages and transfers were the main impetus to convergence; and the highest skilled workers tended to leave poor counties to take employment in the rich. Twio of the most important factors favoring convergence were the migration of retirees from rich counties to poor and the commuting of residents of poor counties to jobs in rich counties.

\section{REFERENCES}

Amos, Orley M., Jr. "Unbalanced Regional Growth and Regional Income Inequality in the Latter Stages of Development." Regional Science and Urban Economics 18 (1988), 549-566.

Arthur, Brian W. "Self-Reinforcing Mechanisms in Economics." In P.W. Anderson, Kenneth J. Arrow, and David Pines (eds.) The Economy as an Evolving Complex System. Santa Fe Institute Studies in the Sciences of Complexity, vol. 5. Reading, MA: Addison-Wesley Publishing Company, 1988.

Barro, Robert J., and Xavier Sala-i-Martin. "Convergence across States and Regions." Brookings Papers on Economic Activity (1991), 107-182.

\footnotetext{
${ }^{10}$ For example, there has been a noticeable tendency for defense companies to protect their contracts from congressional budget hawks by splitting up their operations and installing a plant in every important congressional district .
} 
Beckmann, M. J. Location Theory. New York: Random House, 1968.

Bolton, Roger. "Place Prosperity versus People Prosperity' Revisited: An Old Issue with a New Angle." Urban Studies 29 (1992), 185-203.

Borts, George H., and Jerome L. Stein. Economic Growth in a Free Market. New York: Columbia University Press, 1964.

Browne, Lynn. "Shifting Regional Fortunes: The Wheel Turns." New England Economic Review (May/June 1989), 27-40.

. "Narrowing Regional Income Differentials." New England Economic Review (Sep/Oct 1980a), 48-59.

"Narrowing Regional Income Differentials II." New England Economic Review (Nov/Dec 1980b), 35-56.

Carlino, Gerald A., and Leonard Mills. "Testing Neoclassical Convergence in Regional Incomes and Earnings." Regional Science and Urban Economics 26 (1996), 565-590.

"Convergence and the U.S. States: A Time Series Analysis." Research Working Paper 94-13, Federal Reserve Bank of Philadelphia, 1994.

"Are U.S. Regional Incomes Converging? A Time Series Analysis." Journal of Monetary Economics 32 (1993), 335-346.

Crown, William H., and Leonard F. Wheat. "State per Capita Income Convergence since 1950: Sharecropping's Demise and Other Influences." Journal of Regional Science 35 (1995), 527-552.

Gabriel, Stuart A., Joe P. Mattey, and William L. Wascher. "Compensating Differentials and Evolution of the Quality-of-Life Among U.S. States." Research Working Paper 96-07, Federal Reserve Bank of San Francisco, 1996.

Garnick, Daniel H. "Accounting for Regional Differences in Per Capita Income Growth: An Update and Extension." Survey of Current Business 70 (1990), 29-40.

Garnick, Daniel H., and Howard L. Friedenberg. "Accounting for Regional Differences in Per Capita Personal Income Growth, 1929-79." Survey of Current Business 62 (1982), 24-34.

Hansen, Niles. "The Strategic Role of Producer Services in Regional Development." International Regional Science Review 16 (1994), 187-195.

Hofer, Helmut, and Andreas Worgotter. "Regional Per Capita Income Convergence in Austria." Regional Studies 31 (1997), 1-12.

Hoover, Edgar M. The Location of Economic Activity. New York: McGraw Hill Paperbacks, 1963.

Horn, Gustav A. "On Regional Convergence in a Transitional Economy: The Roles of Migration and Wages." Jahrbucher fur Nationalokonomie und Statistik 212 (1993), 325-340.

Hume, David. Hume's Political Discourses. London: Walter Scott Publishing Co., Ltd., 1906.

Kuznets, Simon. "Economic Growth and Income Inequality." American Economic Review 45 (1955), 1-28. 
Loewy, Michael B., and David H. Papell. "Are U.S. Regional Incomes Converging? Some Further Evidence." Journal of Monetary Economics 38 (1996), 587-98.

Lösch, August. The Economics of Location. Trans. of 2nd ed. New Haven: Yale University Press, 1954.

MacKay, R. Ross. "Non-market Forces, the Nation State and the European Union." Papers in Regional Science 74 (1995), 209-231.

Marshall, Alfred. Principles of Economics. 8th ed. Philadelphia: Porcupine Press, 1920. Maxwell, Philip, and James C. Hite. "The Recent Divergence of Regional Per Capita Incomes: Some Evidence from Australia." Growth and Change 23 (1992), 37-53.

Myrdal, Gunnar. Economic Theory and Under-Developed Regions. London: Gerald Duckworth \& Co., Ltd., 1957.

Ohlin, Bertil. Interregional and International Trade. Rev. ed. Cambridge: Harvard University Press, 1967.

Persson, Joakim. "Convergence across the Swedish Counties, 1911-1993." European Economic Review 41 (1997), 1835-52.

Pritchett, Lant. "Divergence, Big Time." Policy Research Working Paper No. 1522, World Bank. Washington D.C., 1995.

Quah, Danny T. "Regional Convergence Clusters across Europe." European Economic Review 40 (1996), 951-958.

Richardson, Harry W. Regional Economics. Urbana: University of Illinois Press, 1979. Romer, Paul M. "Increasing Returns and Long-Run Growth." Journal of Political Economy 94 (1986), 1002-1037.

Siriopoulos, Costas, and Dimitrios Asteriou. "Testing the Convergence Hypothesis for Greece." Managerial and Decision Economics 18 (1997), 383-89. Slaughter, Matthew J. "Per Capita Income Convergence and the Role of International Trade." American Economic Review 87 (1997), 194-199.

Smith, Adam. An Inquiry into the Nature and Causes of the Wealth of Nations. 5th ed. New York: Modern Library, 1936.

Solow, Robert M. "Technical Change and the Aggregate Production Function." Review of Economics and Statistics 39 (1957), 312-320.

Spiegel, Henry William. The Growth of Economic Thought. 3rd ed. Durham, North Carolina: Duke University Press, 1991.

Thomas, Arthur L. The Allocation Problem in Financial Accounting Theory. Menasha, Wisconsin: George Banta Company, Inc., 1969.

U.S. Department of Commerce, Economics and Statistics Administration, Bureau of Economic Analysis, Regional Economic Analysis Division. Regional Economic Information System 1969-1996. May, 1998.

Williamson, Jeffery G. "Regional Inequality and the Process of National Development: A Description of the Patterns." Economic Development and Cultural Change 13 (1965), 3-46. 
Winnick, Louis. "Place Prosperity versus People Prosperity: Welfare Considerations in the Geographic Redistribution of Economic Activity." In Essays in Urban Land Economics in Honor of the Sixty-Fifth Birthday of Leo Grebler. Los Angeles, California: University of California at Los Angeles, Real Estate Research Program, 1968.

Wojan, Timothy R. "Regional Price Adjustments and Income Convergence: Simultaneity and Welfare Implications of Various Inequality Measures." Paper presented at the. 36th Annual Meeting of the Southern Regional Science Association, Memphis, Tenn., April 1997.

Wojan, Timothy R., and Adam C. Maung. "The Debate over State-Level Inequality: Transparent Methods, Rules of Evidence, and Empirical Power." The Review of Regional Studies 28 (1998), 63-80.

Young, Allyn A. "Increasing Returns and Economic Progress." The Economic Journal 38 (1928), 527-542. 